\title{
Male Sex Workers Selling Physical Sex during the COVID-19 Pandemic in Portugal: Motives, Safer Sex Practices, and Social Vulnerabilities
}

\author{
Henrique Pereira ${ }^{1,2}$ (D) \\ 1 Department of Psychology and Education, Faculty of Social and Human Sciences, University of Beira Interior, \\ 6200-209 Covilhã, Portugal; hpereira@ubi.pt \\ 2 Research Centre in Sports Sciences, Health Sciences and Human Development (CIDESD), \\ 5001-801 Vila Real, Portugal
}

\begin{abstract}
The purpose of this research was to assess the motives, safer sex practices, and vulnerabilities of male sex workers who sold physical sex during the COVID-19 pandemic. This study used a mixed strategy, utilizing purposive sampling techniques to conduct 13 online surveys with male sex workers working in Portugal during the COVID-19 pandemic. Participants were aged between 23 and 47 years old and mostly provided their services to other men. Additionally, half of the participants were immigrants. Participants mentioned paying for essential expenses (rent, food, phone, etc.), having money for day-to-day expenses, wanting to, and enjoying it, as their main motives for engaging in sex work. Regarding sexual practices, 3 to 11 participants did not always or did not consistently use condoms during penetrative sex with their clients. Thematic analysis was used to identify the following repeated patterns of meaning regarding COVID-19-related vulnerabilities, encompassing a loss of clients and income, increased work availability, price reductions and negotiation difficulties, emotional functioning, health care access, safer sex negotiations, age, and immigration status. The findings serve as a basis for recommendations regarding social policies aimed at male sex workers who sell physical sex in Portugal.
\end{abstract}

Workers Selling Physical Sex during the COVID-19 Pandemic in Portugal: Motives, Safer Sex Practices, and Social Vulnerabilities. Societies 2021, 11, 118. https://doi.org/10.3390/ soc11040118

Academic Editors: Sandro Serpa and Carlos Miguel Ferreira

Received: 29 August 2021

Accepted: 22 September 2021

Published: 24 September 2021

Publisher's Note: MDPI stays neutral with regard to jurisdictional claims in published maps and institutional affiliations.

Keywords: male sex workers; commercial sex; COVID-19; motives; practices; vulnerabilities; Portugal

\section{Introduction}

The necessary policies to combat the spread of the Coronavirus Disease 2019 (COVID19), such as social isolation and lockdown measures, have had relevant implications on sexual activity, including commercial sexual activity. In the same way that HIV has created specific challenges for sex workers [1], the COVID-19 pandemic has highlighted the vulnerabilities of their professional activities, which are often associated with stigmatization, criminalization, drug use, violence, mental health challenges, unemployment, homelessness, and difficulties in accessing health care [2]. Sex workers' ability to develop self-protection strategies strongly depends on their social circumstances, namely, the availability of community support [3]. In this regard, sex workers have been able to develop some degree of resilience [4] and to draw attention to their specific needs, despite the obstacles, social exclusion, and oppression fostered by the COVID-19 pandemic.

Although the stereotyped image of sex work is feminine, in reality, it is a heterogeneous activity also practiced by men. The invisibility of male sex work is associated with mechanisms of oppression that are reinforced by sexual stigma, homophobia, and a lack of systematic research [5]. Some of the scientific research regarding male sex workers have focused on sexual health, behavioral risk factors, human immunodeficiency virus (HIV), sexually transmitted infections (STIs) (namely, STI prevalence) [6,7], condom use negotiations [8,9], pre-exposure prophylaxis (PrEP) use [10,11], and network and dyadic characteristics [12], with all factors providing evidence of male sex workers' vulnerabilities. 
The increased use of technology in recent years has created a new digital space for male sex work, making it both more accessible [13] and, simultaneously, more invisible due to the persistence of stigmatizing factors [14]. Many related studies have provided a limited analysis of the transient online profiles of sex workers in these contexts. In turn, this limitation prevents researchers from cultivating a deeper understanding of the reality of online sexual transactions, which probably involve problematic and diverse socioeconomic circumstances motivating sex workers' online presence [15].

Portugal decriminalized sex work in 1983, but a political void remains due to the lack of professional recognition by the state. In addition, the main conceptual understanding of the reality of sex work is through processes of victimization and oppression that are involved in commercial sex [5], accentuating the vulnerability and invisibility of sex workers. The limited prior research regarding male sex work Portugal shows that most sex workers work in apartments or hotels, the majority are young and foreign nationals (mainly Brazilian immigrants), and their main motives for engaging in commercial sex are of a financial nature [16].

In this context, the transformations imposed by the COVID-19 pandemic may have aggravated stigma, discrimination [2-4], the risk of engaging in unprotected sexual activity [17], and difficulties in accessing health care [18], but, above all, access to clients and income [19]. Given that the restrictions associated with the COVID-19 pandemic involved restrictions on people's movements, lockdowns, and stay-at-home orders, it is possible that many male sex workers have witnessed a reduction in their number of clients due to the social isolation measures imposed by health authorities or due to COVID-19 infection fears. Thus, this study was developed to fill the gap left by the lack of studies in Portugal and around the world concerning the motives, practices, and circumstances surrounding the vulnerability of male sex workers who sell physical sex during the COVID-19 pandemic.

\section{Materials and Methods}

This research utilized a mixed methods strategy [20], using purposive sampling techniques [21,22] to conduct 13 online surveys with male sex workers in Portugal during the COVID-19 pandemic. Personal contacts advertised on Portuguese escort websites were made to gain access to the participants. A total of 497 requests to participate were sent through a message containing a link to an electronic survey, which consisted of two parts. The first part contained directed questions concerning participants' sociodemographic information, motives, and safer sexual practices, while the second part included an open-ended question about the impact of COVID-19 on participants' personal and professional lives as a sex worker. The study's methodological foundation was based on a participatory paradigm, promoting an understanding of the relevant determinants for social change [23]. Participation was voluntary, in addition to guaranteeing participants' confidentiality and anonymity.

The data consisted of direct transcripts imported from the information provided by the online survey participants. Thematic analysis was used to identify repeated patterns of meaning [24], framing an epistemologically critical point of view that recognized that male sex work narratives are socially constructed and linked to social oppression [25]. Inductive thematic analysis was conducted using the data obtained from the semantic content and the latent constructs present in participants' written responses [26]. Subsequently, the researcher utilized NVivo software to assist in data analysis, namely, familiarization with the data, generating initial codes, searching for themes, reviewing themes, defining and naming themes, and producing the data report. The author conducted the initial coding and identification, which were later verified, discussed, and refined through coding consistency with two independent experts in the fields of sexuality and psychology. In cases where a match occurred, the researcher and the experts engaged in discussions in order to reach a consensus. 


\section{Results}

\subsection{Sociodemographic Information}

The study recruited 13 male sex workers in Portugal who offered physical sexual services during the COVID-19 pandemic. Data collection took place during the month of January 2021, in the midst of the pandemic's third wave in Portugal, which corresponded to the greatest infection peak in the country and forced the government to impose a general strict lockdown that lasted for several weeks. Participants' ages ranged between 23 and 47 years old, with five identifying themselves as gay, six as bisexual, and two as heterosexual. Seven participants were Portuguese nationals, five were Brazilian immigrants, and one was an Uzbek immigrant. Most men worked with other men, couples, and women, especially at their homes, at clients' homes, at hotels, or online or via online applications. The number of weekly clients varied between 1 and 10. Most participants claimed to be HIV negative, but only six were on PrEP. Table 1 displays participants' sociodemographic information.

\subsection{Motives}

Table 2 provides a more detailed description of sex workers' primary professional motives during the pandemic. The most important motives mentioned were wanting to, paying for essential expenses (rent, food, phone, etc.), having money for day-to-day expenses, because sex work is exciting, and enjoying it. Table 2 displays additional motives for engaging in sex work mentioned by participants.

\subsection{Sexual Practices}

As shown in Table 3, only $61.5 \%$ of participants claimed that they always used a condom when engaging in vaginal sex, $76.9 \%$ for insertive anal sex, and $61.5 \%$ for receptive anal sex. This finding signifies that participants partook in a considerable number of sexual activities involving penetrative sex that implied elevated HIV and STI transmission risks.

\subsection{Social Vulnerabilities}

\subsubsection{Loss of Customers and Income}

All participants reported that the main impact of the COVID-19 pandemic was a drop in their number of customers and, consequently, a drop in income. This reduction in clients may have been related to the consequences of health policies that limited social interactions through lockdowns and stay-at-home orders. These policies could have deterred clients from seeking out sex workers' services, while simultaneously encouraging sex workers to take precautionary measures to avoid COVID-19 infection risks. All participants exercised their professional activities online and, given that sex work is not legally regulated in Portugal, participants were unable to request government financial support to assist with any financial difficulties that may have arisen as a result of the pandemic. Moreover, most participants were single and lived alone, increasing the likelihood of lacking family, friends, or social support networks, thus intensifying isolation experiences. The aforementioned findings are illustrated by select participant quotations below:

"I have a lot of difficulties paying my daily bills, rent, electricity, water, Internet, food, transportation ... My few savings are running out, and I have no way to save enough to pay my expenses ... All because customers have decreased dramatically. Now, if I manage to get 3 or 4 customers in a week, it is already very good, while, before the pandemic, I could easily have had 15."

Sex worker \#4, 27 years old, bisexual, Brazilian immigrant.

"There has been a big drop in calls. My biggest source of income is from trips outside Lisbon, namely to Madrid, Paris, and Rome. With airports closed, I was trapped in a city where customers do not have enough money to pay for my services."

Sex worker \#3, 37 years old, gay, Brazilian immigrant. 
Table 1. Sociodemographic Information.

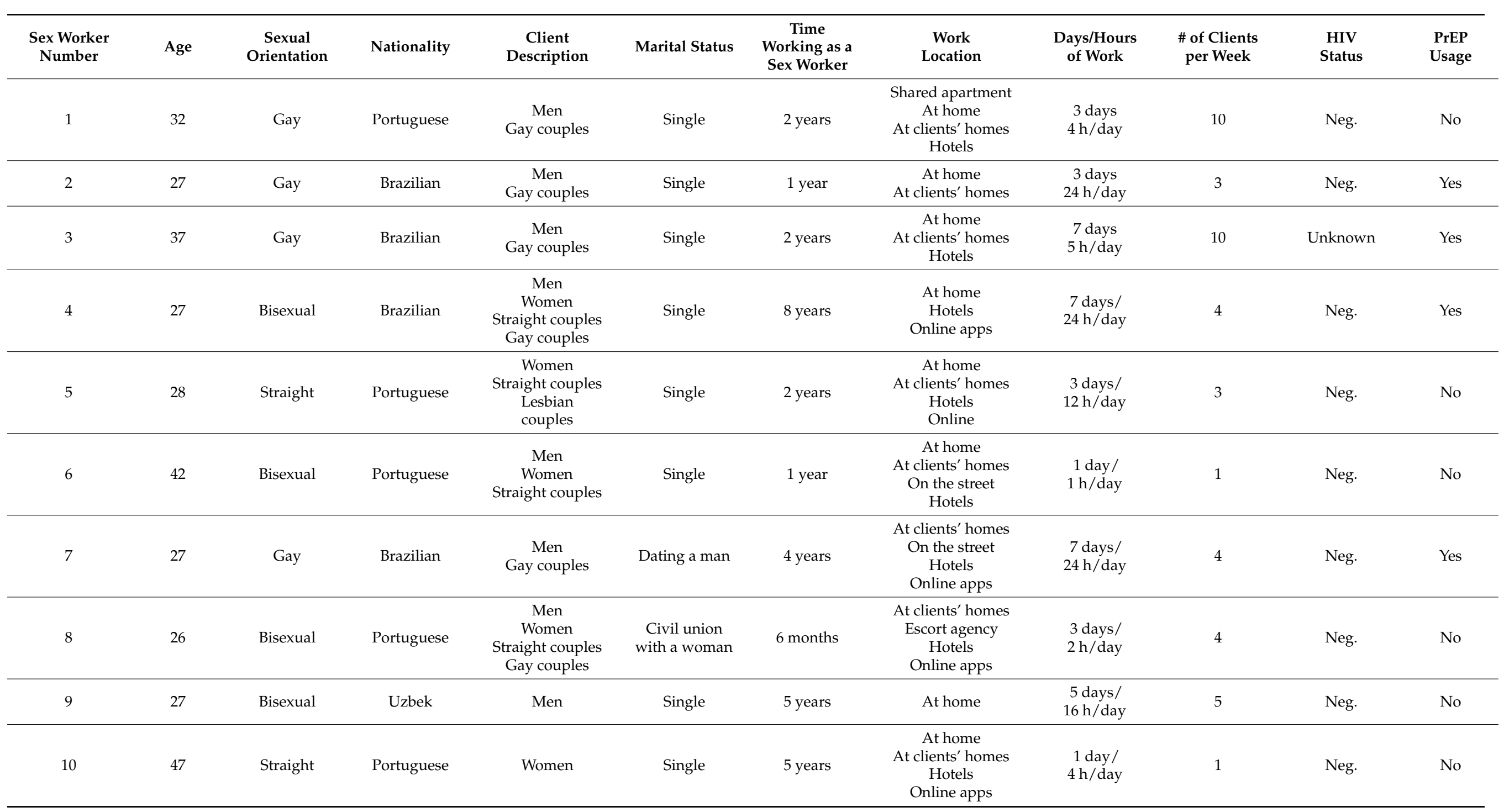


Table 1. Cont.

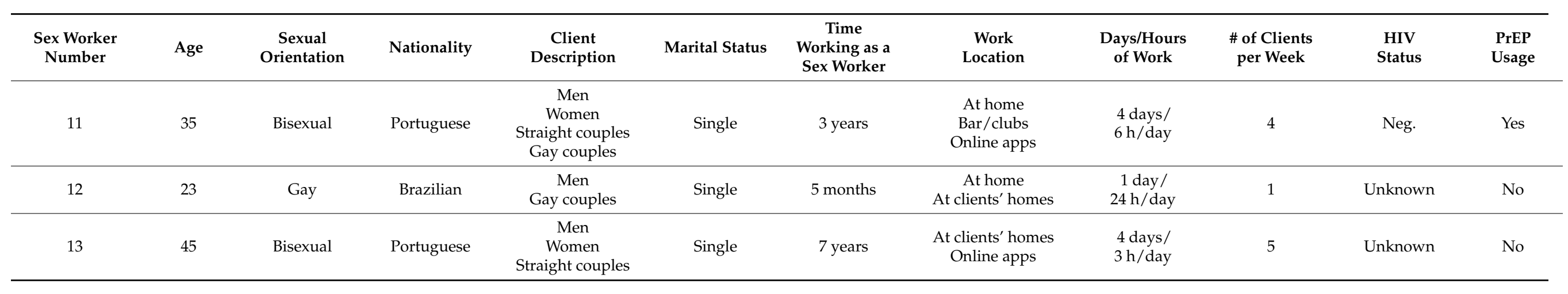

Table 2. Sex Work Motives during the Pandemic.

\begin{tabular}{|c|c|c|c|c|c|}
\hline & $\begin{array}{c}\text { Not Important at All } \\
n(\%)\end{array}$ & $\begin{array}{c}\text { Somewhat Unimportant } \\
n(\%)\end{array}$ & $\begin{array}{l}\text { Neutral } \\
n(\%)\end{array}$ & $\begin{array}{c}\text { Somewhat Important } \\
n(\%)\end{array}$ & $\begin{array}{c}\text { Very Important } \\
n(\%)\end{array}$ \\
\hline To pay for essential expenses (rent, food, phone, etc.) & $2(15.4 \%)$ & $1(7.7 \%)$ & $0(0 \%)$ & $2(15.4 \%)$ & $8(61.5 \%)$ \\
\hline To afford luxuries, social life, etc. & $6(46.2 \%)$ & $1(7.7 \%)$ & $0(0 \%)$ & $3(23.1 \%)$ & $3(23.1 \%)$ \\
\hline To pay for school & $5(38.4 \%)$ & $0(0 \%)$ & $3(23.1 \%)$ & $3(23.1 \%)$ & $2(15.4 \%)$ \\
\hline To help family & $7(53.8 \%)$ & $1(7.7 \%)$ & $1(7.7 \%)$ & $1(7.7 \%)$ & $3(23.1 \%)$ \\
\hline To have sexual experiences & $1(7.7 \%)$ & $1(7.7 \%)$ & $5(38.4 \%)$ & $2(15.4 \%)$ & $4(30.7 \%)$ \\
\hline A lack of family financial support & $5(38.4 \%)$ & $0(0 \%)$ & $1(7.7 \%)$ & $4(30.7 \%)$ & $3(23.1 \%)$ \\
\hline Influence of friends & $11(84.6 \%)$ & $1(7.7 \%)$ & $1(7.7 \%)$ & $0(0 \%)$ & $0(0 \%)$ \\
\hline Because it is exciting & $1(7.7 \%)$ & $0(0 \%)$ & $0(0 \%)$ & $6(46.2 \%)$ & $6(46.2 \%)$ \\
\hline To finance a gambling problem & $13(100 \%)$ & $0(0 \%)$ & $0(0 \%)$ & $0(0 \%)$ & $0(0 \%)$ \\
\hline To finance an alcohol problem & $13(100 \%)$ & $0(0 \%)$ & $0(0 \%)$ & $0(0 \%)$ & $0(0 \%)$ \\
\hline To finance a drug problem & $13(100 \%)$ & $0(0 \%)$ & $0(0 \%)$ & $0(0 \%)$ & $0(0 \%)$ \\
\hline To have money for day-to-day expenses & $1(7.7 \%)$ & $1(7.7 \%)$ & $0(0 \%)$ & $3(23.1 \%)$ & $8(61.5 \%)$ \\
\hline To make my own schedule & $6(46.2 \%)$ & $0(0 \%)$ & $0(0 \%)$ & $4(30.7 \%)$ & $3(23.1 \%)$ \\
\hline Lack of other qualifications/skills & $10(76.9 \%)$ & $0(0 \%)$ & $1(7.7 \%)$ & $1(7.7 \%)$ & $1(7.7 \%)$ \\
\hline Because I like it & $0(0 \%)$ & $0(0 \%)$ & $3(23.1 \%)$ & $3(23.1 \%)$ & $7(53.8 \%)$ \\
\hline I don't know how to leave & $11(84.6 \%)$ & $0(0 \%)$ & $2(15.4 \%)$ & $0(0 \%)$ & $0(0 \%)$ \\
\hline
\end{tabular}


Table 3. Sexual Practices with Clients.

\begin{tabular}{|c|c|c|c|c|c|}
\hline & $\begin{array}{l}\text { Never } \\
n(\%)\end{array}$ & $\begin{array}{c}\text { Rarely } \\
n(\%)\end{array}$ & $\begin{array}{c}\text { Sometimes } \\
n(\%)\end{array}$ & $\begin{array}{l}\text { Frequently } \\
\quad n(\%)\end{array}$ & $\begin{array}{c}\text { Always } \\
n(\%)\end{array}$ \\
\hline $\begin{array}{l}\text { Condom use for } \\
\text { vaginal sex }\end{array}$ & $0(0 \%)$ & $1(7.7 \%)$ & $1(7.7 \%)$ & $3(23.1 \%)$ & $8(61.5 \%)$ \\
\hline $\begin{array}{l}\text { Condom use for } \\
\text { anal sex (insertive) }\end{array}$ & $0(0 \%)$ & $2(15.4 \%)$ & $0(0 \%)$ & $1(7.7 \%)$ & $10(76.9 \%)$ \\
\hline $\begin{array}{l}\text { Condom use for } \\
\text { anal sex (receptive) }\end{array}$ & $0(0 \%)$ & $3(23.1 \%)$ & $1(7.7 \%)$ & $1(7.7 \%)$ & $8(61.5 \%)$ \\
\hline $\begin{array}{l}\text { Condom use for } \\
\text { oral sex (active) }\end{array}$ & $5(38.4 \%)$ & $3(23.1 \%)$ & $1(7.7 \%)$ & $2(15.4 \%)$ & $2(15.4 \%)$ \\
\hline $\begin{array}{l}\text { Condom use for } \\
\text { oral sex (passive) }\end{array}$ & $3(23.1 \%)$ & $5(38.4 \%)$ & $1(7.7 \%)$ & $2(15.4 \%)$ & $2(15.4 \%)$ \\
\hline $\begin{array}{l}\text { Condom use when } \\
\text { using sex toys }\end{array}$ & $2(15.4 \%)$ & $1(7.7 \%)$ & $5(38.4 \%)$ & $0(0 \%)$ & $5(38.4 \%)$ \\
\hline
\end{tabular}

"I have experienced a drastic drop in income, even after trying to maximize opportunities to get more customers, especially over the Internet and by increasing service times. But, it has not been easy because they do not show up. I have no one to ask for help, as I do not speak to my family members, they do not know about my profession, and I live alone. Even some friends and former clients with whom I had a closer connection are also experiencing financial difficulties and cannot help me ... There are days when I have to resort to community support services for essential goods."

Sex worker \#5, 28 years old, straight, Portuguese national.

\subsubsection{Increased Work Availability}

Almost all participants significantly increased their professional availability during the pandemic, even during lockdowns or following increases in COVID-19 cases, with the exceptions of sex workers \#10 and \#12, who limited their services. Additionally, participants stated that they employed careful attitudes regarding COVID-19 prophylactic measures, namely, using masks and disinfectant gel, as well as frequently sanitizing their workspaces.

"I started to be available $24 \mathrm{~h}$ a day, 7 days a week. I advertise my services by reinforcing hygienic measures and ensuring, that they [clients] are safe with me, as much as possible." Sex worker \#4, 27 years old, bisexual, Brazilian immigrant.

"Now, I usually work $72 \mathrm{~h}$ in a row, and I go everywhere-to clients' houses, hotels and guest houses, over the Internet, and even on the street."

Sex worker \#7, 27 years old, gay, Brazilian immigrant.

\subsubsection{Price Reductions and Negotiation Difficulties}

Some participants reported that they have had to cut prices and even deal with problematic customers that did not want to or could not pay for their services. The pandemic also significantly impacted the customers of paid sex services and, as a result, exacerbated sex workers' economic vulnerability, as well as threats to their physical and emotional integrity.

"I started to include the possibility of charging 'low-cost' prices to try to get more clients. In comparison with before the pandemic, I have had many more customers leave without paying because they are more aggressive and upset about the pandemic and because they do not even have money."

Sex worker \#8, 28 years old, bisexual, Portuguese national. 


\subsubsection{Emotional Functioning}

Some participants reported that the pandemic and social isolation measures imposed by the government did not affect them greatly from an emotional point of view. Explanations encompassed personal reasons, such as possessing an introverted personality, fixed habits at home, and having managed to adjust to the changes imposed on their routines.

"On a personal level, I think that [social] isolation did not affect me much, as I am already naturally a homebody. I simply adapted to new circumstances."

Sex worker \#1, 32 years old, gay, Portuguese national.

"As I work mostly at home, and I am very much a homebody, I managed the need to be isolated at home well. Of course, I go out, especially to go to customers' houses or to the supermarket, but I also started doing more shopping online to stay sane."

Sex worker \#7, 27 years old, gay, Brazilian immigrant.

However, most participants reported having felt very relevant emotional impacts, not only due to income declines that generated financial problems, but also in relation to inherent pandemic-related anxieties, such as infection fears, the distress resulting from significant behavioral changes that were imposed by lockdown measures, and even existential questions.

"The pandemic has affected my life a lot, [and] it has worsened all aspects of my existence. I became more vulnerable, afraid, anxious, and even depressed. I am in a very complicated situation, mentally. It is not easy for me to deal with isolation, [and] I feel distraught and disoriented. I find myself feeling a lack of interest in the things around me, but I force myself to get up every day, so as not to lose heart."

Sex worker \#11, 35 years old, bisexual, Portuguese national.

"The main problem is the loss of contact with friends and family. I completely lost my social life and that makes me feel very lonely and disoriented. I have not seen my children in many months ..."

Sex Worker \#13, 45 years old, bisexual, Portuguese national.

"It has forced me to reflect on my life values, [and] it has forced me to examine my decisions and think about past bitterness. Unfortunately, it did not help to solve anything. On the contrary, I became more isolated and felt greater uncertainty about my life plans."

Sex worker \#5, 28 years old, straight, Portuguese national.

\subsubsection{Health Care Access}

In Portugal, even during the most severe periods of prophylactic isolation, health care access was never limited due to the COVID-19 pandemic. However, some participants reported that they had to adjust their schedules in response to postponements and changes, in order to obtain health care access.

"The pandemic forced me to better manage my time in order to keep myself healthy. For example, PrEP or STI testing appointments have become more limited during the lockdowns, but these always involve a certain number of unforeseen events, delays, and postponements, which is understandable given these circumstances."

Sex worker \#7, 27 years old, gay, Brazilian immigrant.

Other participants indicated that they sometimes needed to use sildenafil for work. Given the limitations imposed by pandemic-related restrictions, the online pharmaceutical market became a solution to purchase this medication.

"We men do not run at full speed all the time. As I work $24 \mathrm{~h}$ in a row, sometimes I have to take that pill in order to work. Fortunately, we can buy it online, easily and discreetly."

Sex worker \#2, 27 years old, gay, Brazilian immigrant. 


\subsubsection{Safer Sex Negotiations}

Some participants, even those not on PrEP, mentioned the need to resort to the possibility of partaking in unsafe sexual practices, as requested by some clients. Agreeing to engage in unsafe sexual practices was viewed as a means of attracting more clients and, thus, minimizing any negative effects on income.

"I have had this job for two years, and I have never had an HIV test, so I do not know if I am positive or not. If a client wants to pay a little more to have unprotected sex, I will not say no. I think the responsibility is his."

Sex worker \#3, 37 years old, gay, Brazilian immigrant.

"I am HIV-negative and I am on PrEP. So, I feel a little safer when a client asks me to have unprotected sex. I try to convince them that it is better to use a condom, but that is not always possible because some men really insist. Nowadays, you cannot be picky, [and] we have to take advantage of everything that comes our way."

Sex worker \#7, 27 years old, gay, Brazilian immigrant.

However, some participants also reported never having sex without a condom. In some cases, this was due to the fact that they were involved in romantic relationships, while, in other cases, they cited the high value they attributed to their health.

"I have only been involved in this life for 6 months. It was really necessary to survive due to the pandemic. My girlfriend knows about it, and the one essential condition that she imposed on me was to always use a condom."

Sex worker \#6, 26 years old, bisexual, Portuguese national.

"My health is priceless. Even if things are going badly, I will not have sex without a condom. I have been working in this field for 5 years, and this is a fundamental rule in my profession. Without a condom, there is no deal. I am STI-free and I want to continue that way."

Sex worker \#9, 27 years old, bisexual, Uzbek immigrant.

\subsubsection{Age}

Three of the study participants were over 40 years old (aged 42, 45, and 47, respectively). In their cases, they often pointed out age-related discrimination as a professional obstacle that aggravated the customer shortage caused by the COVID-19 pandemic. Ageism is present in society, and it may have increased negative aging experiences among some of our participants, in addition to the stigma associated with sex work.

"In this competitive market, younger people are more successful. It frustrates me a lot, but I have to accept it. If I were in my twenties, I think it would be different ... I try to use other advantages, since I work with a female audience, [and] I have to use age and experience as a charm factor ..."

Sex worker \#10, 47 years old, straight, Portuguese national.

"I have been doing this for a long enough time (7 years) to understand the dynamics. Customers prefer younger guys. And, with the pandemic, older people will be left behind. That is how it works. Sometimes, I think about giving up, but also, what is my alternative?"

Sex worker \#13, 45 years old, bisexual, Portuguese national.

\subsubsection{Immigration}

Poor economic conditions, national security issues, and a lack of respect for sexual minority rights in migrants' countries of origin could be the principal migration motives for several of our participants. However, several found their destination country to be facing a highly vulnerable economic situation due to the pandemic and were unable to find jobs, while others were unable to gain legal migration status, creating a context of 
enormous socioeconomic fragility. For many, paid sexual activity was their only means of survival.

"I arrived in Portugal 7 months ago, right in the middle of the pandemic. As an immigrant without many academic or professional qualifications, I could not find a job and my savings only lasted for 2 months. I ran out of money. I had to enter this life in order to survive. There is discrimination because we are immigrants, coupled with discrimination against being gay and being a sex worker."

Sex worker \#12, 23 years old, gay, Brazilian immigrant.

"I was unable to find work during the pandemic, and I cannot legalize myself without a formal employment contract. I have been living in the country illegally for over a year, and I had to do this job to survive."

Sex worker \#2, 27 years old, gay, Brazilian immigrant.

\section{Discussion}

This research explored the motives, safer sex practices, and vulnerabilities of selfemployed male sex workers selling physical sex in Portugal during the COVID-19 pandemic. This research provides important contributions to understanding the effects of the COVID-19 pandemic on an activity that is already highly invisible and subject to increased risks and vulnerability. Regarding motives for selling sex during the COVID-19 pandemic, most participants highlighted wanting to or enjoying sex work, as well as financial reasons, such as paying essential bills and having money for daily expenses. As in previous studies [27], this study found that practical, financial, and intrinsic (wanting to or enjoying sex work) reasons were the most prevalent motives for male sex workers to engage in paid sexual activity. Previous studies have confirmed these results, underlining the importance of men's economic conditions when deciding to partake in sex work [28,29].

The COVID-19 pandemic has created an unprecedented economic crisis that has forced many men to start working as sex workers to pay for their basic needs and everyday expenses. However, others indicated that they also engaged in sex work because they viewed it as an exciting and flexible activity. This combination of factors suggests that male sex work is not an inherently negative experience among the participants. This finding contrasts with those of earlier studies [30], which have highlighted the negative experiences associated with the cost-benefit negotiations between the positive and negative factors inherent to the nature of sex work, encompassing managing potential problems with clients, psychological problems, stigma toward sex work, adverse economic and employment conditions, and a lack of formal recognition by the state [27]. Thus, as previously demonstrated [31], it is clear that many men's motives for engaging in sex work arose from the economic conditions created by changes related to the COVID-19 pandemic [4].

In regard to participants' sexual practices, an evidently significant number of participants (5 to 11) do not always or consistently use condoms when partaking in penetrative sexual practices with their clients. Increasing evidence has shown that there are several facilitators that can increase the frequency of unprotected sexual activity between male sex workers and their clients, including biological, behavioral, and structural determinants [7,32]. However, very little research has been carried out on this topic regarding male sex workers. On the one hand, clients may request that condoms not be used due to the fact that they are men who often do not identify as gay or bisexual, may have regular female sexual partners, and may not be informed about the importance of having safer sex with other men. On the other hand, several of our participants indicated that they use and are knowledgeable about PrEP, which may allow them to lower their guard in relation to condom use [33]. In Portugal, PrEP is currently available at hospitals that are part of the HIV hospital referral network, and PrEP prescriptions must be written by infectious disease specialists after assessing patients at a high risk of acquiring HIV or other sexually transmitted infections (namely, sex workers), after obtaining patients' 
informed consent [34]. Thus, it is clear that it is of the utmost importance to support more systematic educational and informational efforts concerning PrEP access, in addition to safer sex health campaigns aimed at male sex workers in Portugal. These policies could not only encourage behavioral change, but also might promote innovative interventions suitable to the complexity of these interactions, with the aim of reducing HIV and STI risk exposure among both male sex workers and their clients.

Participants manifested several vulnerabilities in this study's discourse analysis. All men highlighted poverty-related risks and a decrease in income and customers. Participants' vulnerabilities were reinforced by their need to make major professional adaptations, such as increasing available working hours or reducing prices, as well as the more frequent difficulties they encountered in negotiating payments, which demonstrated their increased exposure to poverty, hunger, and violence in the context of pandemic-related lockdowns and stay-at-home orders. As illustrated by other studies that evaluated COVID-19's impacts on sex work, these vulnerabilities can increase poverty risks, as well as the need to work at home, which may lead to confusion surrounding safety precautions and an increased risk of violence [19]. Thus, this research highlights the social disadvantages faced by male sex workers in Portugal, particularly in the context of the COVID-19 pandemic.

Contrary to earlier studies' findings [17], participants did not present excessive consumption of toxic substances, homelessness, or severe mental illness during the COVID-19 pandemic, although some presented emotional difficulties associated with social isolation and a lack of social support. This finding may be related to male sex workers' ability to adapt to the adversities imposed by the pandemic, particularly their resilience in dealing with survival needs [4]. In fact, as demonstrated by other studies [35], working as a male sex worker is not related to any serious mental health problems, and the presence of emotional difficulties among participants is more likely related to the context of the COVID-19 pandemic, as it requires difficult adjustment efforts that can result in anxious, depressive, and post-traumatic symptoms [36]. In the context of sex work, restrictions imposed by governments to try to contain the COVID-19 pandemic caused major obstacles to sex workers' access to specific health care needs [36], although this finding was not communicated by our participants. The Portuguese government has maintained health care appointment access, as well as access to PrEP appointments and online access to medications, although sex workers' specific COVID-19-related health care needs were not explicitly taken into account [3].

Participants also referred to the accumulation of stigma factors, namely, age and country of origin, in addition to the stigma associated with sex work, as factors of increased vulnerability. In fact, a significant percentage of participants were immigrants and three were over 40 years old. Immigration involves a series of changes, adjustments, and cultural adaptations, which can increase stress levels associated with those already experienced due to the pandemic. For sex workers, these processes also involve specific migration trajectories that are embedded in body, gender, sex, and sexuality representations [37], comprising dynamics that future studies should examine in greater detail. Regarding age, risks include the possibility of having fewer customers and, consequently, reduced income flows, as well as enhanced poverty and vulnerability risks. However, the need to manage both the positive and negative perceptions associated with aging [38] could also be seen as an opportunity.

This investigation contributed to findings showing that the COVID-19 pandemic imposed important changes on male sex work in Portugal, creating worrying consequences of vulnerability associated with stigma and invisibility. These vulnerabilities were exacerbated by the lack of formal research into sex work and an absence of legal regulations that would allow for a better evaluation of sex workers' specific needs. These results contrast with those found by studies in the Netherlands and Belgium, where the state regulates sex work [39], calling attention to the need to legalize this activity in Portugal. As demonstrated by this study, the combination of various vulnerabilities accentuated by the COVID-19 pandemic warrants further research designed to explore the pandemic's impacts and how 
it may affect other male sex workers in Portugal. Further research could also examine how to implement specific actions to minimize infection risks, such as limiting face-to-face contact or wearing a mask during sexual activity [2], in addition to encouraging lawmakers to assign priority to this population during vaccination campaigns.

This research possesses some limitations. It utilized a small sample collected online through sex service sites for men, and, consequently, it is not representative of all sex workers who sell physical sex in Portugal. Furthermore, most participants were gay or bisexual causing the study sample to underrepresent sex workers who work primarily with women. Finally, the specific context associated with the study's timing, carried out at the peak of the COVID-19 pandemic in Portugal, may have intensified some participants' narratives and views. Future studies should try to monitor the effects of the COVID-19 pandemic on male sex workers' quality of life over time.

\section{Conclusions}

Male sex workers are key populations who are often affected by stigma that can negatively impact their health and well-being [40]. One of the most insidious consequences of such stigma is its ability to curtail the capacity of sex workers to fight for basic human rights, especially in a country like Portugal where the political void makes sex workers face a range of barriers when accessing health care services, justice services, and victim and protection services, perpetuating experiences of discrimination and their exclusion from employment legislation. In addition, following a participatory paradigm [41], this study highlights the need to involve male sex workers in the design, implementation and evaluation of interventions that concern them, thus allowing for a sense of control so much need in times of vulnerability such as those inflicted by the COVID-19 pandemic.

Male sex workers who sell physical sex during the COVID-19 pandemic in Portugal are a diverse population. Regardless of their sexual orientation, they mostly offer sex to men, and many are at risk of acquiring HIV or being exposed to an increased burden of HIV in the context of the global COVID-19 pandemic. The intersectional stigmas of same-sex practices, commercial sex, and HIV, and the impediment of selling sex due to the government imposed stay-at-home measures have increased the likelihood HIV and STI risk [33,42]. Ongoing efforts to distribute PrEP to at-risk male sex workers should be made available in order to minimize the complex barriers that hinder the consistent use of condoms.

This study's findings serve as a basis for social policy recommendations aimed at male sex workers who sell physical sex in Portugal. Although not criminalized, sex work is an activity burdened with stigma that should be regulated and dignified. Most participants exercise this activity because they want to and because it is their primary means of sustenance. However, a lack of recognition and legal regulation prevents sex work from being treated as a normal job. In turn, this results in a context characterized by an enhanced lack of protection and greater vulnerability, as shown by sex workers' inability to access state subsidies to compensate for financial losses related to the COVID-19 pandemic. On the other hand, sex workers possess specific needs concerning health-related vulnerabilities, especially in relation to the adoption of safer sex practices and discrimination, such as ageism and xenophobia. Thus, the study results point to the need to create policies whose impacts extend beyond the context of the COVID-19 pandemic to facilitate the protection, visibility, and validation of male sex workers who sell physical sex in Portugal.

Funding: This research received no external funding.

Institutional Review Board Statement: The study was conducted according to the guidelines of the Declaration of Helsinki and approved by the Ethics Committee of the University of Beira Interior (Portugal) (code CE-UBI-Pj-2020-088).

Informed Consent Statement: Informed consent was obtained from all subjects involved in the study.

Data Availability Statement: The data presented in this study are available upon request. 
Conflicts of Interest: The author declares no conflict of interest.

\section{References}

1. Shannon, K.; Crago, A.-L.; Baral, S.; Bekker, L.-G.; Kerrigan, D.; Decker, M.R.; Poteat, T.; Wirtz, A.L.; Weir, B.; Boily, M.-C.; et al. The global response and unmet actions for HIV and sex workers. Lancet 2018, 392, 698-710. [CrossRef]

2. Singer, R.; Crooks, N.; Johnson, A.K.; Lutnick, A.; Matthews, A. COVID-19 Prevention and Protecting Sex Workers: A Call to Action. Arch. Sex. Behav. 2020, 49, 2739-2741. [CrossRef]

3. Platt, L.; Elmes, J.; Stevenson, L.; Holt, V.; Rolles, S.; Stuart, R. Sex workers must not be forgotten in the COVID-19 response. Lancet 2020, 396, 9-11. [CrossRef]

4. Lam, E. Pandemic sex workers' resilience: COVID-19 crisis met with rapid responses by sex worker communities. Int. Soc. Work. 2020, 63, 777-781. [CrossRef]

5. Oliveira, A. Same work, different oppression: Stigma and its consequences for male and transgender sex workers in Portugal. Int. J. Iber. Stud. 2018, 31, 11-26. [CrossRef]

6. Callander, D.; Read, P.; Prestage, G.; Minichiello, V.; Chow, E.P.F.; Lewis, D.; McNulty, A.; Ali, H.; Hellard, M.; Guy, R.; et al. A cross-sectional study of HIV and STIs among male sex workers attending Australian sexual health clinics. Sex. Transm. Infect. 2016, 93, 299-302. [CrossRef]

7. Pereira, H. Male Sex Workers in Lisbon, Portugal: A Pilot Study of Demographics, Sexual Behavior, and HIV Prevalence. J. AIDS Clin. Res. 2014, 5. [CrossRef]

8. Biello, K.B.; Thomas, B.E.; Johnson, B.E.; Closson, E.F.; Navakodi, P.; Dhanalakshmi, A.; Menon, S.; Mayer, K.H.; Safren, S.A.; Mimiaga, M.J. Transactional sex and the challenges to safer sexual behaviors: A study among male sex workers in Chennai, India. AIDS Care 2016, 29, 231-238. [CrossRef] [PubMed]

9. Valente, P.K.; Mantell, J.E.; Masvawure, T.B.; Tocco, J.U.; Restar, A.J.; Gichangi, P.; Chabeda, S.V.; Lafort, Y.; Sandfort, T.G. "I Couldn't Afford to Resist": Condom Negotiations Between Male Sex Workers and Male Clients in Mombasa, Kenya. AIDS Behav. 2019, 24, 925-937. [CrossRef]

10. MacGibbon, J.; Minichiello, V.; Prestage, G.; Bell, S.; Cox, C.; Donovan, B.; Callander, D. How Male Sex Workers and Their Clients Shifted from Reluctance About HIV Pre-exposure Prophylaxis to Advocating for Its Use: A Longitudinal Mixed Methods Study. AIDS Behav. 2019, 24, 782-790. [CrossRef]

11. Restar, A.J.; Tocco, J.U.; Mantell, J.E.; Lafort, Y.; Gichangi, P.; Masvawure, T.B.; Chabeda, S.V.; Sandfort, T.G.M. Perspectives on HIV Pre- and Post-Exposure Prophylaxes (PrEP and PEP) Among Female and Male Sex Workers in Mombasa, Kenya: Implications for Integrating Biomedical Prevention into Sexual Health Services. . AIDS Educ. Prev. 2017, 29, 141-153. [CrossRef]

12. Biello, K.B.; Goedel, W.C.; Edeza, A.; Safren, S.A.; Mayer, K.H.; Marshall, B.D.; Latkin, C.; Mimiaga, M.J. Network-Level Correlates of Sexual Risk Among Male Sex Workers in the United States: A Dyadic Analysis. JAIDS J. Acquir. Immune Defic. Syndr. 2020, 83, 111-118. [CrossRef] [PubMed]

13. Minichiello, V.; Scott, J.; Callander, D. New Pleasures and Old Dangers: Reinventing Male Sex Work. J. Sex Res. 2013, 50, 263-275. [CrossRef] [PubMed]

14. Kuhar, R.; Pajnik, M. Negotiating Professional Identities: Male Sex Workers in Slovenia and the Impact of Online Technologies. Sex. Res. Soc. Policy 2018, 16, 227-238. [CrossRef]

15. Grov, C.; Koken, J.; Smith, M.; Parsons, J.T. How do male sex workers on Craigslist differ from those on Rentboy? A comparison of two samples. Cult. Heal. Sex. 2016, 19, 405-421. [CrossRef]

16. Pereira, H. Homens que Vendem Sexo em Portugal [Men who sell sex in Portugal]. Atas do VI Congresso Português de Sociologia. 2008. Available online: http:/ / associacaoportuguesasociologia.pt/vicongresso/pdfs/795.pdf (accessed on 4 February 2021).

17. Beima-Sofie, K.; Ortblad, K.F.; Swanson, F.; Graham, S.M.; Stekler, J.D.; Simoni, J.M. “Keep It Going if You Can”: HIV Service Provision for Priority Populations During the COVID-19 Pandemic in Seattle, WA. AIDS Behav. 2020, 24, 2760-2763. [CrossRef]

18. Gichuna, S.; Hassan, R.; Sanders, T.; Campbell, R.; Mutonyi, M.; Mwangi, P. Access to Healthcare in a time of COVID-19: Sex Workers in Crisis in Nairobi, Kenya. Glob. Public Health 2020, 15, 1430-1442. [CrossRef]

19. Kimani, J.; Adhiambo, J.; Kasiba, R.; Mwangi, P.; Were, V.; Mathenge, J.; Macharia, P.; Cholette, F.; Moore, S.; Shaw, S.; et al. The effects of COVID-19 on the health and socio-economic security of sex workers in Nairobi, Kenya: Emerging intersections with HIV. Glob. Public Health 2020, 15, 1073-1082. [CrossRef] [PubMed]

20. Denzin, N.; Lincoln, Y. Strategies of Qualitative Inquiry; Sage: London, UK, 2008.

21. Palinkas, L.A.; Horwitz, S.; Green, C.; Wisdom, J.; Duan, N.; Hoagwood, K. Purposeful Sampling for Qualitative Data Collection and Analysis in Mixed Method Implementation Research. Adm. Policy Ment. Health Ment. Health Serv. Res. 2013, 42, 533-544. [CrossRef]

22. Welch, J.K.; Patton, M.Q. Qualitative Evaluation and Research Methods. Mod. Lang. J. 1992, 76, 543. [CrossRef]

23. Simon, W.; Gagnon, J.H. Sexual scripts. In Culture, Society and Sexuality: A Reader, 2nd ed.; Parker, R., Aggleton, P., Eds.; Routledge: New York, NY, USA, 2007; pp. 31-40.

24. Braun, V.; Clarke, V.; Terry, G. Thematic analysis. In Qualitative Research in Clinical and Health Psychology; Rohleder, P., Lyons, A., Eds.; Palgrave Macmillan: Basingstoke, UK, 2015; pp. 95-113.

25. Joffe, H. Thematic analysis. In Qualitative Methods in Mental Health and Psychotherapy: A Guide for Students and Practitioners; Harper, D., Thompson, A.R., Eds.; Wiley: Chichester, UK, 2011; pp. 209-223. 
26. Braun, V.; Clarke, V. Using thematic analysis in psychology. Qual. Res. Psychol. 2006, 3, 77-101. [CrossRef]

27. Sagar, T.; Jones, D.; Symons, K.; Tyrie, J.; Roberts, R. Student involvement in the UK sex industry: Motivations and experiences. Br. J. Sociol. 2016, 67, 697-718. [CrossRef]

28. Roberts, R.; Sanders, T.; Myers, E.; Smith, D. Participation in sex work: Students' views. Sex Educ. 2010, 10, 145-156. [CrossRef]

29. Sanders, T.; Hardy, K. Students Selling Sex: Marketisation, Higher Education and Consumption. Br. J. Sociol. Educ. 2014, 36, 747-765. [CrossRef]

30. Griffith, J.D.; Mitchell, S.; Hart, C.L.; Adams, L.T.; Gu, L.L. Pornography Actresses: An Assessment of the Damaged Goods Hypothesis. J. Sex Res. 2013, 50, 621-632. [CrossRef] [PubMed]

31. Krüsi, A.; Chettiar, J.; Ridgway, A.; Abbott, J.; Strathdee, S.A.; Shannon, K. Negotiating Safety and Sexual Risk Reduction With Clients in Unsanctioned Safer Indoor Sex Work Environments: A Qualitative Study. Am. J. Public Health 2012, 102, 1154-1159. [CrossRef] [PubMed]

32. Baral, S.D.; Friedman, M.R.; Geibel, S.; Rebe, K.; Bozhinov, B.; Diouf, D.; Sabin, K.; Holland, C.E.; Chan, R.; Caceres, C. Male sex workers: Practices, contexts, and vulnerabilities for HIV acquisition and transmission. Lancet 2014, 385, 260-273. [CrossRef]

33. Edeza, A.; Galárraga, O.; Santamaria, E.K.; Sosa-Rubí, S.; Operario, D.; Biello, K.B. “I Do Try To Use Condoms, But ... ": Knowledge and Interest in PrEP Among Male Sex Workers in Mexico City. Arch. Sex. Behav. 2019, 49, 355-363. [CrossRef] [PubMed]

34. PrEP Watch. A snapshot of PrEP Scale-Up, Registration and Resources for Portugal. Available online: https://www.prepwatch. org/country/portugal/ (accessed on 4 February 2021).

35. Weiss, P. Mental Health and Sexual Identity in a Sample of Male Sex Workers in the Czech Republic. Med. Sci. Monit. 2014, 20, 1682-1686. [CrossRef]

36. WHO. Mental Health \& COVID-19. Available online: https://www.who.int/teams/mental-health-and-substance-use/covid-19 (accessed on 19 September 2020).

37. Valadier, C. Migration and Sex Work through a Gender Perspective. Context. Int. 2018, 40, 501-524. [CrossRef]

38. Pereira, H.; Serrano, J.P.; De Vries, B.; Esgalhado, G.; Afonso, R.M.; Monteiro, S. Aging Perceptions in Older Gay and Bisexual Men in Portugal: A Qualitative Study. Int. J. Aging Hum. Dev. 2017, 87, 5-32. [CrossRef]

39. Azam, A.; Adriaenssens, S.; Hendrickx, J. How Covid-19 affects prostitution markets in the Netherlands and Belgium: Dynamics and vulnerabilities under a lockdown. Eur. Soc. 2020, 23, S478-S494. [CrossRef]

40. Oselin, S.S. Challenging Stigma: Identity Talk among Male Sex Workers in a Recovery Program. Sociol. Perspect. 2018, 61, 240-256. [CrossRef]

41. Graça, M.; Gonçalves, M.; Martins, A. Action research with street-based sex workers and an outreach team: A co-authored case study. Action Res. 2017, 16, 251-279. [CrossRef]

42. Fitzgerald-Husek, A.; Van Wert, M.J.; Ewing, W.F.; Grosso, A.L.; Holland, C.E.; Katterl, R.; Rosman, L.; Agarwal, A.; Baral, S. Measuring stigma affecting sex workers (SW) and men who have sex with men (MSM): A systematic review. PLoS ONE 2017, 12, e0188393. [CrossRef] 